\title{
Repensando as Fronteiras entre Espiritualidade e Terapia: Reflexões sobre a "cura" no Santo Daime
}

\author{
Isabel Santana de Rose A EXPANSÃO DO SANTO DAIME E SUA INSERÇÃO NO “MUNDO \\ UFSC DAS DROGAS"
}

Santo Daime é uma expressão multivocal, ou seja, pode ter vários significados. Referese a um movimento religioso que teve início entre as décadas de 20 e 40 no estado do Acre e a partir da década de 80 expandiu-se por todo o Brasil e posteriormente para o exterior. 0 termo Santo Daime referencia também dois grupos religiosos: Alto Santo e Centro Eclético de Fluente Luz Universal Raimundo Irineu Serra, ou CEFLURIS 1 .

Além disso, Santo Daime é o nome que os participantes deste movimento religioso dão à bebida que consomem em seus rituais ${ }^{2}$. $O$ daime é produzido pela cocção de duas plantas nativas da floresta amazônica: o cipó Banisteriopsis caapi e a folha do arbusto Psychotria viridis, chamados pelos participantes do Santo Daime de "jagube" e "rainha", respectivamente. Esta bebida é considerada como um "ser divino", dotado de personalidade própria e capaz de curar e de transmitir conhecimento.

A disseminação do Santo Daime para além da região amazônica coloca a questão do relacionamento deste movimento religioso com a sociedade mais ampla. Para Sandra Goulart (2004), um dos impactos desta disseminação é a inserção cada vez maior da utilização da ayahuasca ${ }^{3}$ na discussão sobre o tema das "drogas". De acordo com ela, a expansão das religiões que têm como uma de suas bases o consumo ritualizado de substâncias psicoativas traz à tona novos modos de pensar estas substâncias.

Por outro lado, a expansão do Santo Daime, acompanhada pela inclusão do debate a respeito do uso da ayahuasca na discussão sobre a temática contemporânea das "drogas", tem impactos importantes também no âmbito deste campo religioso. 
como um todo, do Estado, de pesquisadores e da mídia. O Estado, utilizando a lógica da política proibicionista às "drogas", chegou a incluir por um período a ayahuasca na lista de substâncias proscritas pela lei

A disseminação do Santo Daime e sua inclusão no que Gilberto Velho (1999) chamou de "mundo das drogas" também tem outra importante implicação. Como mostrou Velho (1997), o consumo das substâncias que na sociedade contemporânea costumam ser classificadas como "drogas" atualmente está relacionado à valorização de alguns destes produtos. Esta valorização afeta seu consumo, que passa a ser ditado pelas lógicas do mercado.

No caso do Santo Daime, estas questões aqui levantadas tem duas importantes conseqüências. Primeiro, a interferência do Estado gera uma negociação com este movimento religioso - tanto em nível nacional quanto internacional - a respeito da legalidade do consumo da ayahuasca; das condições de extração das plantas que são utilizadas para confeccionar a bebida; e das condições de seu preparo e transporte. Em segundo lugar, a inserção da ayahuasca numa lógica de mercado levanta importantes discussões sobre a questão da comercialização de uma substância que costuma ser considerada "sagrada" pelos grupos que a utilizam.

\section{USO "TERAPÊUTICO" DA AYAHUASCA NO CONTEXTO DO SANTO DAIME}

No Brasil, a ayahuasca é utilizada por três grupos religiosos distintos: Santo Daime, União do Vegetal ${ }^{7}$ e Barquinha ${ }^{8}$. A legalidade da utilização desta bebida está baseada no status "religioso" de seu consumo. Enquanto os usos definidos como "rituais" e "religiosos" têm atualmente um status legal, os usos considerados "terapêuticos" se encontram numa espécie de "vácuo legal", não sendo regulamentados por nenhum tipo de medida9. Apesar disso, a utilização terapêutica da ayahuasca vem se disseminando em vários contextos.

Um exemplo deste uso direcionado para fins terapêuticos pode ser encontrado no livro de Beatriz Labate (2004), no qual ela faz uma etnografia de um grupo de "neoayahuasqueiros urbanos" chamado Caminho do Coração, enfocando a descrição da trajetória do líder deste grupo. Segundo Labate, a utilização da ayahuasca no Caminho do Coração se distinguiria devido a seu viés marcadamente terapêutico. Seu líder se define como terapeuta e, entre outras atividades, realiza psicoterapia com daime com seus clientes, que também participam dos rituais do Caminho do Coração (Labate 2004).

Neste artigo, pretendo refletir a respeito das fronteiras que costumam ser comumente estabelecidas entre "espiritualidade" e "terapia"10 a partir de observações realizadas nas minhas pesquisas. Fiz meu trabalho de campo numa comunidade daimista chamada Céu da Mantiqueira. Esta comunidade é filada ao CEFLURIS (Centro Eclético de Fluente Luz Universal Raimundo Irineu Serra) e localiza-se no sul do estado de Minas Gerais, perto da cidade de Camanducaia. Ao contrário do grupo estudado por Labate (2004), que é caracterizado por realizar uma "reinvenção" da utilização da ayahuasca, a comunidade que eu pesquisei enquadra-se dentro dos moldes do CEFLURIS, que é a principal organização responsável pela expansão nacional e internacional da doutrina daimista e é vista como sendo "tradicional". Apesar disto, o Céu da Mantiqueira também se caracteriza por um viés que poderia ser considerado "terapêutico". 
O Céu da Mantiqueira foi fundado em 1998, tendo antes funcionado como "ponto" desde 1993"1. Ao longo da trajetória desta comunidade, vários acontecimentos apontam para a construção e reconstrução de uma identidade coletiva enquanto "centro de cura". Esta identidade encontra-se ancorada na história do grupo, em interação com a praxis de seus participantes. Conta-se que quando foram iniciados os trabalhos espirituais com o Santo Daime neste lugar, os "guias" e "mentores espirituais" se manifestaram através dos médiuns que estavam presentes e disseram que ali era um "centro de cura". Hoje, o Céu da Mantiqueira é definido pelos seus próprios participantes como um "centro de cura". A temática da cura tem, portanto, importância fundamental para este grupo, constituindo um dos eixos que contribuem para construir sua identidade e sua especificidade.

Atualmente são realizados no Céu da Mantiqueira todos os meses dois rituais definidos como sendo direcionados especificamente para a cura, os trabalhos de Cura e Mesa Branca. O primeiro é considerado como um trabalho da "corrente espiritual"12, durante o qual os participantes buscam contatar o seu "Eu Superior"13 e também os seres espirituais para receber instruções, orientações e curas. Esta cura pode ser dos participantes, da "corrente", ou mesmo de pessoas ausentes. Já o trabalho de Mesa Branca é caracterizado pela grande influência do espiritismo kardecista. Ele também é chamado de trabalho de "banca aberta", pois é aberto para a incorporação de espíritos, visando o desenvolvimento mediúnico de seus participantes. O desenvolvimento mediúnico é incentivado e é considerado como fazendo parte do processo terapêutico e de auto-conhecimento (Labate 2002). Estes dois rituais são considerados como sendo muito importantes pelos participantes do Céu da Mantiqueira e têm um papel fundamental na dinâmica do grupo.

Além disso, os participantes do Céu da Mantiqueira utilizam uma ampla gama de procedimentos terapêuticos ${ }^{14}$ provenientes de diferentes campos, como da própria cultura daimista; da biomedicina; de grupos indígenas; de outras tradições religiosas e das chamadas "terapias alternativas". Também chama a atenção a presença de um número expressivo de pessoas que trabalham profissionalmente na área da saúde entre os participantes da comunidade ${ }^{15}$.

\section{O "SISTEMA DE CUIDADOS DA SAÚDE" DO CÉU DA MANTIQUEIRA}

Conheci o Céu da Mantiqueira no ano 2000 e em 2001 comecei a fazer trabalho de campo lá para realizar minha monografia de conclusão de curso (Rose 2002). Dei prosseguimento a esta pesquisa durante o mestrado, sendo que durante o ano de 2004 passei quatro meses morando na comunidade para, através da observação participante, levantar os dados para elaborar minha dissertação (Rose 2005).

Na minha pesquisa, procurei levantar e analisar as principais categorias culturais envolvidas na experiência dos processos de cura, saúde e doença para os participantes do Céu da Mantiqueira. Para fazer esta análise, utilizei o conceito de "sistema de cuidados da saúde", proposto por Arthur Kleinman (1980). Kleinman sugere que as práticas de cuidados da saúde, inclusive a biomedicina, sejam vistas como sistemas culturais. Segundo este autor, 
os componentes fundamentais dos "sistemas de cuidados da saúde" são os "curadores" e os "pacientes". Para Kleinman, eles não podem ser compreendidos fora deste contexto. Ele considera que a doença e a cura também fazem parte do "sistema de cuidados da saúde". De acordo com este autor, dentro deste sistema, estas categorias são articuladas como experiências culturalmente construídas.

Segundo Kleinman, as crenças sobre a saúde e a doença estão sempre ligadas a intervenções terapêuticas específicas, constituindo, assim, sistemas de conhecimento e ação. Desta maneira, elas não podem ser entendidas separadamente da forma como são colocadas em prática. Kleinman (1980) divide o sistema de cuidados da saúde em três setores, que chama de popular, folk e professiona ${ }^{16}$. De acordo com ele, em cada um desses settings, a doença é percebida, interpretada e rotulada de determinada maneira, e formas diferentes de cuidado são aplicadas.

Para fazer uma análise do "sistema de cuidados da saúde" do Céu da Mantiqueira, realizei um levantamento dos principais procedimentos terapêuticos utilizados pelos participantes desta comunidade. Como vimos, estes procedimentos terapêuticos são provenientes de diferentes campos: da cultura daimista, de outras tradições religiosas, de grupos indígenas, das chamadas terapias "alternativas" e da biomedicina. Estamos, portanto, diante de um "sistema de cuidados da saúde" que pode ser considerado como um sistema plural (Kleinman 1980), ou seja, oferece uma variedade de opções terapêuticas aos indivíduos que estão inseridos nele.

Para fins analíticos, dividi os procedimentos terapêuticos utilizados pelos participantes do Céu da Mantiqueira em dois grupos: os do primeiro grupo estão mais relacionados ao que chamei de "pólo da espiritualidade", enquanto os do segundo grupo estão mais ligados ao "pólo da terapia".

\section{PÓLO DA ESPIRITUALIDADE}

\section{Uso de tinturas feitas de ervas e flores}

No Céu da Mantiqueira, as tinturas feitas de plantas e flores podem ser utilizadas na igreja, durante os rituais, quando são aspergidas no recinto, ou podem ser usadas individualmente, sendo passadas no corpo em pequenas quantidades ou administradas via oral. Essas tinturas são utilizadas há cerca de um ano em caráter experimental. Seu uso tem como base as propriedades das plantas que as compõem. Assim, plantas consideradas estimulantes, como o alecrim, são utilizadas em momentos nos quais se sente que a "corrente" está precisando de um estímulo; já plantas consideradas calmantes, como o hortelã e a menta, são usadas para trazer tranqüilidade.

\section{Banhos de ervas e chás}

É muito difundido entre os participantes do Céu da Mantiqueira o hábito de tomar "banhos de ervas", tanto antes quanto depois dos rituais e no dia a dia. Acredita-se que os banhos de ervas e flores têm o poder de "limpar" ${ }^{17}$ e 
"descarregar" o "aparelho"18, ajudando a mantê-lo livre das influências negativas. Também é difundido o hábito de tomar chás, que podem ou não ter finalidades terapêuticas.

\section{Florais da Amazônia}

Os florais da Amazônia consistem num sistema de essências florais desenvolvido por participantes do Santo Daime que residem no Céu do Mapiá19. De acordo com Isabel Barsé e Maria Alice Freire, as principais responsáveis pelo desenvolvimento deste sistema de florais, eles são confeccionados a partir de essências de plantas nativas da floresta Amazônica e também de plantas cultivadas. Elas afirmam também que a utilização desses florais pode possibilitar uma "evolução da consciência" (Freire \& Barsé 2000). Acredita-se que os florais da Amazônia atuem nos "corpos sutis" ${ }^{20}$, reequilibrando as energias.

\section{Kambô}

Kambô ${ }^{21}$ é a designação dos sapos Phyllomedusa bicolor, Phyllomedusa tarsius e Phyllomedusa vaillantii, usados por vários povos indígenas do Alto Juruá (AC), tais como os Katukina, Kaxinawá, Yaminawá e Ashaninka. Estes grupos usam o kambô especialmente para "tirar panema"22 e tornar o caçador feliz, embora ele também seja considerado por alguns povos como remédio para muitos males (Souza et al 2005). Segundo Souza et al, "os grupos de língua Pano, bem como os seringueiros, usam o que chamam de 'injeção de sapo' como estímulo sobretudo para os caçadores e seus cachorros. Provocam-se pequenas feridas na pele, em geral com queimaduras, e esfrega-se a substância do dorso do sapo nessas feridas. Cada uma delas é um 'ponto'" (2005: 608).

Edilene Coffaci de Lima e Beatriz Labate (2005) tratam da expansão urbana do uso do kambô que ocorre, segundo elas, não apenas em diversas cidades do Acre, mas também em grandes centros. As autoras afirmam que nos centros urbanos o kambô é exaltado sobretudo como um "remédio indígena" e tem um uso diferente do verificado nas aldeias. Segundo Lima e Labate, a divulgação do kambô fora do Acre é realizada por intermédio de adeptos das religiões ayahuasqueiras, de neo-ayahuasqueiros e de personagens ligados ao movimento da Nova Era, como terapeutas holísticos e neo-xamãs. As autoras mencionam, inclusive, o uso do kambô em comunidades daimistas.

O uso do kambô no Céu da Mantiqueira pode ser visto como mais um exemplo de como neste contexto elementos vindos de outros sistemas médicos são interpretados de acordo com a lógica daimista. Os participantes do Céu da Mantiqueira referem-se ao kambô como uma "vacina" e consideram que ela deve ser tomada preferencialmente antes ou depois de um ritual. As fortes reações geradas pela "vacina" - tais como taquicardia, sensação de inchaço corporal, forte pulsação na cabeça, falta de ar, vômitos e diarréias - possibilitariam dissolver bloqueios nos níveis físico, mental, emocional e espiritual. Desta maneira, o kambô é visto como sendo capaz de produzir uma grande "limpeza" no "aparelho" e compreendido a partir da lógica da "cura espiritual". 


\section{PÓLO DA TERAPIA}

\section{Psicoterapia}

Um dos desdobramentos relevantes da inserção dos profissionais ligados à área da saúde no Céu da Mantiqueira é o desenvolvimento de uma tendência das pessoas que participam da comunidade a se tratarem com participantes do mesmo grupo, principalmente de fazerem psicoterapia com os psicólogos e psiquiatras. De acordo com relatos, entrevistas e observações de campo, o que distingue este tipo de terapia é a possibilidade de levar em conta também aspectos espirituais, que seriam ignorados por grande parte dos profissionais da saúde e que, para os participantes do Santo Daime, representam uma dimensão fundamental da vida.

A disseminação da terapia entre os participantes do Céu da Mantiqueira levanta questões a respeito de qual o tipo de relação que se desenvolve entre os terapeutas que fazem parte desta comunidade e seus pacientes. Esta relação também pode nos fornecer pistas sobre o modelo espiritual-terapêutico que vem sendo construído no Céu da Mantiqueira. Um dos fatores enfatizados pelos profissionais da área da saúde em suas narrativas é a existência de uma cumplicidade entre eles e seus pacientes que também participam do Santo Daime. Esta cumplicidade pode estar relacionada ao fato de pertencerem à mesma "comunidade simbólica"23, compartilhando experiências, crenças, valores e práticas em comum.

Nas narrativas das pessoas que trabalham profissionalmente na área da saúde também é recorrente a noção de que eles estão passando por um "processo de cura dentro da doutrina", o que possibilitaria que eles compreendam melhor seus pacientes. Este é mais um elemento que contribui, neste contexto, para criar uma cumplicidade entre terapeutas e pacientes. Isto nos remete à idéia expressa por Paula Montero (1985) de que o lugar daquele que cura está em continuidade com o lugar daquele que está doente. Assim, para esta autora, é a ambivalência do papel do curador que lhe permite servir como mediador entre o estado de doença e o de cura. De acordo com Montero, na Umbanda, o adepto tende a passar por uma experiência de doença antes de se tornar médium, o que significa que os que detêm o direito de produzir atos terapêuticos têm seu poder fundado no fato de que viveram experiências semelhantes às de quem eles se propõem curar. Da mesma maneira, podemos pensar que o que permite que os profissionais da área da saúde que participam do Céu da Mantiqueira sirvam como mediadores das experiências rituais de seus pacientes é o fato de também vivenciarem experiências semelhantes.

A partir de uma análise das práticas de cura desenvolvidas nos terreiros de Candomblé, Andréa Caprara (1998) faz uma discussão sobre a questão da relação médico/paciente. Ela utiliza o conceito de "médico ferido" desenvolvido por Gadamer (1994 citado em Caprara 1998) para discutir "a necessidade de uma maior sensibilidade por parte do médico frente ao sofrimento do paciente e a transformação da prática médica, dirigida para uma medicina mais humana" (1998: 124).

Segundo Caprara, no Candomblé o tema do terapeuta sensível à dor e ao sofrimento do paciente se manifesta de maneira profunda devido à presença de terapeutas que vivenciaram eles próprios um processo de doença, de 
sofrimento e de cura. Ela também afirma que "a dupla polaridade da figura doente com poderes de cura é freqüente nas representações e práticas tradicionais" (1998: 124).

A partir da discussão feita por Caprara e das reflexões a respeito de como se dão as relações médico/paciente entre os participantes do Céu da Mantiqueira, podemos pensar que um dos elementos que distinguem este tipo de terapia é a possibilidade de permitir que os pacientes expressem aflições e sofrimentos que não seriam considerados legítimos em outros contextos. Assim, a cumplicidade existente entre terapeutas e pacientes, devida ao fato de compartilharem experiências, valores, práticas e crenças em comum e de considerarem que estão passando por um "processo de cura" na doutrina daimista, implica a criação de um "idioma" que permita comunicar mais proximamente (e trabalhar na psicoterapia) as experiências relacionadas à espiritualidade.

Por outro lado, é preciso considerar que a existência de uma "cumplicidade" entre terapeutas e pacientes tem também seus aspectos problemáticos. Como vimos, um dos elementos que contribui para gerar esta "cumplicidade" é o fato de terapeutas e pacientes participarem da mesma "comunidade simbólica", ou seja, terem relações de proximidade. Vários profissionais da área da saúde que eu entrevistei enfatizaram a existência de uma grande proximidade entre eles e seus pacientes, afirmando que estes, além de participarem da mesma comunidade, muitas vezes são seus amigos. O estabelecimento simultâneo de relações religiosas, de amizade e de terapeuta-paciente aparecia como um problema para os próprios profissionais da saúde, que afirmavam ter que rever suas práticas para poderem se enquadrar a esta situação.

Além disso, é importante levar em conta que estes profissionais da área da saúde são representantes do que Kleinman (1980) chamou de "setor profissional" do "sistema de cuidados de saúde". A ênfase que a sociedade ocidental contemporânea coloca neste setor pode ter uma influência na posição que estes profissionais têm dentro de uma comunidade que procura construir uma identidade como um "centro de cura". De fato, eu observei que no Céu da Mantiqueira os profissionais da área da saúde têm um status importante, tendo o papel de: a) diagnosticar as pessoas que não podem tomar daime ${ }^{24}$; b) orientar os participantes dos rituais sobre a compatibilidade entre medicamentos e a bebida ${ }^{25}$; c) observar os participantes dos rituais, podendo conversar com eles quando acham que há necessidade; e d) receitar medicação alopática ou outros tipos de tratamento. Estes dados indicam que estas pessoas têm uma posição de poder dentro da comunidade e apontam para a possibilidade de que, em muitos casos, elas possam ter também funções de controle.

\section{Medicalização}

A disseminação da psicoterapia entre os participantes do Céu da Mantiqueira é acompanhada por um amplo uso dos medicamentos alopáticos. Isto me levou a pensar sobre uma possível influência do processo de medicalização no "sistema de cuidados de saúde" desta comunidade. Os profissionais da área da saúde que participam do Céu da Mantiqueira não vêem o uso de medicação alopática e a ingestão do daime como antagônicos, pelo contrário, há uma recorrência da idéia de que, dependendo do caso, esta medicação é necessária e mesmo indispensável. 
Todos os profissionais da área da saúde que eu entrevistei afirmaram que atendem tanto participantes do Santo Daime quanto pessoas que não participam da doutrina e todos afirmaram também que percebem grandes diferenças entre o processo terapêutico dos dois tipos de pacientes. Com relação à questão do uso da medicação alopática, uma das psiquiatras que eu entrevistei afirmou que percebe uma diferença entre os pacientes que ela medica que tomam daime e os que não tomam. De acordo com ela, muitas vezes os que não tomam o daime não conseguem mais ficar sem a medicação, enquanto os que participam da doutrina precisam da medicação apenas por um período para ajudar em momentos difíceis, conseguindo prosseguir depois sem precisar dela.

Desta maneira, assim como os outros procedimentos terapêuticos utilizados, a medicação alopática é encarada como uma ferramenta que pode ser um "auxiliar" potencial em casos de necessidade. Neste contexto, o daime é visto como um "grande remédio", uma "medicina universal" que pode curar todas as doenças (Groisman \& Sell 1996), e os outros procedimentos terapêuticos utilizados são vistos como "ferramentas auxiliares".

\section{Psicoterapia com daime}

Um pequeno grupo de pessoas que trabalham profissionalmente na área da saúde e estão ligadas ao Céu da Mantiqueira está desenvolvendo um trabalho de psicoterapia com daime que eles chamam de "cura xamânica". Este trabalho consiste em uma sessão especial, realizada dentro de um processo terapêutico mais amplo. $O$ paciente e os terapeutas escolhem juntos, durante o processo terapêutico, uma questão com a qual o paciente tem mais dificuldade, para ser trabalhada nesta sessão. A sessão de psicoterapia com daime tem uma duração longa, de três a quatro horas, e costuma ser realizada por dois terapeutas em conjunto. De acordo com um dos profissionais da saúde que realiza este trabalho, nesta sessão a ampliação de consciência proporcionada pelo daime é direcionada para trabalhar o ponto no qual o paciente tem dificuldade.

Esta sessão de psicoterapia é definida pelos profissionais da área da saúde que a realizam como um "ritual". De acordo com eles, no espaço em que a sessão é realizada existe um altar com imagens das principais lideranças daimistas (Mestre Irineu, Padrinho Sebastião etc.) e objetos que costumam estar presentes no altar da igreja (cruzeiro, velas, incenso etc.). Também são utilizados outros elementos característicos da doutrina daimista, como orações e hinos. Além disso, os terapeutas podem "receber entidades" para orientar o paciente e também para indicar o que deve ser feito na sessão. Paralelamente, podem ser utilizadas técnicas provenientes da psicologia, da psiquiatria e das "terapias alternativas", como terapia de vidas passadas, por exemplo.

Durante a sessão de "cura xamânica", tanto os terapeutas quanto o paciente tomam o daime. De acordo com um desses profissionais da saúde, exatamente o que vai acontecer dentro da sessão é imprevisível, pois quem decide, quem diz o que precisa ser feito, é o daime, e não o terapeuta. Nas suas palavras, “o daime é o cirurgião e eu sou o bisturi. É ele que vai dizer o que eu vou fazer". Outro profissional da área da saúde afirma que neste trabalho todo seu conhecimento técnico é "entregue ao mestre", para que o terapeuta possa ser orientado 
pelos guias da doutrina. Ele também afirma que está "aprendendo como trabalhar com esse estado ampliado de consciência dentro do contexto terapêutico".

Este exemplo da psicoterapia com daime é paradigmático para refletirmos a respeito das fronteiras entre espiritualidade e terapia. Através das narrativas dos profissionais da área da saúde que realizam este trabalho, vemos que a sessão de psicoterapia é definida como um ritual. Além do próprio daime, são utilizados elementos característicos da doutrina daimista, como o altar, hinos e orações. Além disso, os terapeutas podem "receber" seus "guias" e "entidades" para orientar o paciente ou para dizer o que deve ser feito na sessão. Estes elementos característicos da doutrina daimista encontram-se combinados com técnicas e procedimentos advindos da psicologia e da psiquiatria. A partir deste exemplo, podemos perceber que neste contexto não é possível separar o que seria "propriamente espiritual" do que seria "propriamente terapêutico".

François Laplantine (1991) questiona a divisão entre antropologia da saúde e antropologia da religião. O autor sugere que esta distinção está fundada numa compreensão etnocêntrica. Para Laplantine, as duas áreas devem ser articuladas para que categorias como saúde, doença e cura possam ser compreendidas. De acordo com ele, todo fenômeno, médico ou religioso, é sempre um "fenômeno social total" (1991: 214) e envolve, além destas duas dimensões, dimensões políticas e econômicas, entre outras. Laplantine considera, portanto, que existem relações entre a doença e o sagrado, a medicina e a religião, a saúde e a salvação.

Para o autor, um exemplo do relacionamento entre estas dimensões se encontra nas "situações terapêuticas nas quais aquilo que nós indicamos por religioso e o que chamamos de médico estão estreitamente ligados" (1991: 214). De acordo com Laplantine, esta dimensão religiosa também existe na biomedicina, porém ela não é percebida pela sociedade, devido à aparente autonomia entre medicina e religião. Este autor afirma que "não existem práticas puramente 'médicas' ou puramente 'mágico-religiosas'" (1991: 217). Para ele, quase sempre existem "dois níveis interpretativos estreitamente ligados: uma interpretação concernente aos processos etiológico-terapêuticos, uma interpretação concernente ao sentido e ao porquê" da doença (idem).

\section{O CONTINUUM ESPIRITUAL-TERAPÊUTICO}

A análise do "sistema de cuidados da saúde" do Céu da Mantiqueira mostrou que neste contexto não é possível separar o que é "propriamente terapêutico" do que é "propriamente espiritual", pois estas duas dimensões encontram-se intimamente relacionadas. Procurei, então, construir um modelo que pudesse dar conta desta estreita imbricação entre espiritualidade e terapia. Este modelo está baseado em dois processos simultâneos e complementares que observei no Céu da Mantiqueira.

O primeiro destes processos foi definido como terapeutização da espiritualidade ${ }^{26}$. Este processo está relacionado à integração das pessoas que trabalham profissionalmente na área da saúde no Céu da Mantiqueira e 
ao desenvolvimento de uma tendência de que os participantes desta comunidade procurem profissionais da área da saúde ligados ao Santo Daime. Assim, a terapia, categoria proveniente da biomedicina e das "terapias alternativas", torna-se um valor entre os participantes do Céu da Mantiqueira. Neste contexto, porém, este valor é ressignificado segundo a lógica própria da cosmologia daimista. O que se enfatiza é a combinação entre o Santo Daime e a terapia. Considera-se que a terapia paralela à participação na doutrina teria os efeitos de "catalisar", "aprofundar" e "acelerar" o processo terapêutico. Também se afirma que este tipo de terapia pode ajudar a compreender as experiências vivenciadas nos rituais daimistas, auxiliando no desenvolvimento espiritual.

O segundo processo identificado foi definido como a espiritualização dos procedimentos terapêuticos. Neste processo, a espiritualidade, valor fundamental na cosmologia daimista e também no universo da Nova Era, torna-se uma parte importante do idioma e dos procedimentos terapêuticos das pessoas que trabalham profissionalmente na área da saúde e que estão ligadas ao Céu da Mantiqueira. As entrevistas que eu realizei com estes profissionais mostram que o fato destes participarem do Santo Daime torna-se um marco importante em suas vidas, modificando tanto sua prática profissional quanto sua vida pessoal.

É importante ressaltar que o Céu da Mantiqueira está inserido numa "rede ayahuasqueira urbana" (Labate 2004), por onde circulam pessoas, valores e substâncias. Esta rede, por sua vez, está relacionada ao universo da Nova Era, de forma que os valores de ambos estes circuitos se interpenetram e se influenciam mutuamente. Segundo Sônia Maluf, estamos diante da "emergência de um vasto campo de intersecção entre novas formas de espiritualidade e práticas terapêuticas alternativas" (2003: 1), no qual existe uma "dupla implicação entre o terapêutico e o espiritual" (idem). O estudo do caso do Céu da Mantiqueira evidencia esta implicação. Neste contexto, se pensarmos em termos de um continuum entre o espiritual e o terapêutico, ambos os pólos do continuum se influenciam. A substância que circula entre os dois pólos, formando o continuum, é constituída fundamentalmente pelos valores provenientes tanto do pólo da espiritualidade quanto do pólo da terapia. Estes valores, por sua vez, fundamentam os procedimentos espirituais e terapêuticos.

Desta maneira, enquanto no processo de terapeutização da espiritualidade os valores característicos da biomedicina e das práticas terapêuticas chamadas de "alternativas" interagem com os valores característicos da doutrina daimista, influenciando-os, no processo de espiritualização da terapia os valores e categorias característicos da doutrina daimista influenciam as práticas dos profissionais da área da saúde que participam do Céu da Mantiqueira e os procedimentos terapêuticos, modificando-os e adaptando-os ao novo contexto.

Considero que os valores englobantes provêm da doutrina daimista. São estes valores que vão orientar a lógica segundo a qual os procedimentos terapêuticos provenientes de outros campos são incorporados ao "sistema de cuidados da saúde" do Céu da Mantiqueira. Isto está relacionado à ênfase êmica dada tanto ao daime quanto à doutrina daimista. Como vimos, o daime é considerado como uma "medicina universal" que pode curar todos os tipos de doenças (Groisman e Sell 1996). Os procedimentos terapêuticos são vistos como "ferramentas auxiliares". Neste contexto, estes procedimentos são reinterpretados e ressignificados. 
Para compreender esta estreita imbricação entre espiritualidade e terapia que observei no Céu da Mantiqueira e também a opção por determinados tipos de terapia neste contexto, é importante levar em conta qual é a noção de "cura" para os participantes desta comunidade. Este conceito de "cura" é mais amplo que o biomédico, referindose também a outras dimensões que vão além do "corpo físico" ${ }^{27}$ e colocando uma grande ênfase na "dimensão espiritual"28. As explicações sobre a causalidade das doenças abrangem dimensões que não são enfatizadas pela biomedicina e permitem preencher outras funções além da propriamente terapêutica.

Segundo Groisman e Sell (1996), o paradigma terapêutico dominante na doutrina daimista não é alopático, ou seja, não está centrado na remissão dos sintomas das doenças. Desta maneira, a remissão dos sintomas não constitui necessariamente um indicador concreto da "cura", da mesma forma que a morte de uma pessoa não significa que ela não tenha sido "curada" (Peláez 1996). Para Groisman e Sell, o conceito daimista de cura deve ser considerado como um evento mais complexo do que apenas um evento orgânico, pois envolve o ser humano como um todo e inclui tanto relações com os outros seres vivos quanto relações cósmicas.

É a compreensão do porquê da doença, considerada como um "trabalho interior", que pode gerar uma mudança nos hábitos e comportamentos, conferindo às pessoas a oportunidade de ter novas perspectivas sobre a vida (Groisman \& Sell 1996). É neste sentido que podemos pensar na importância da "cura espiritual" (Peláez 1996). A doutrina daimista pode ser vista como um meio ou um "caminho" para se obter esta "cura espiritual" (Peláez 1996). Assim, a preocupação com a "dimensão espiritual" representa um fator fundamental nos procedimentos terapêuticos utilizados pelos participantes do Céu da Mantiqueira e influencia consideravelmente as práticas dos profissionais da área da saúde que participam desta comunidade.

\section{REFLEXÕES FINAIS}

Partindo das considerações feitas por Laplantine (1991), podemos pensar que o modelo do continuum espiritualterapêutico que elaborei observando a estreita imbricação entre o espiritual e o terapêutico que existe no Céu da Mantiqueira poderia ser estendido também a outros "sistemas de cuidado da saúde". A diferença seria que na biomedicina ocidental contemporânea convencional, procura-se manter uma ruptura entre a doença e o discurso religioso e, desta maneira, entre a relação da doença com o social (Laplantine 1991) ${ }^{29}$. Já as análises que fiz do "sistema de cuidados da saúde" do Céu da Mantiqueira mostram que, neste contexto, o que se procura é enfatizar esta relação entre as dimensões terapêutica e espiritual. Desta maneira, os diferentes procedimentos terapêuticos disponíveis fornecem um "idioma" que permite a expressão das experiências relacionadas à espiritualidade, considerada pelos participantes do Santo Daime como uma dimensão fundamental da vida. 
Considero que a imbricação entre o espiritual e o terapêutico que observei no Céu da Mantiqueira pode constituir um indício da construção de um "novo" modelo terapêutico também num contexto mais amplo. Como mostrou Maluf (2003), atualmente esta intersecção entre novas formas de espiritualidade e procedimentos terapêuticos "alternativos" abrange um vasto campo que chamei de "rede terapêutico-espiritual alternativa". Este modelo, diferentemente do modelo biomédico convencional, enfatiza a necessidade de equilíbrio e integração entre as várias dimensões que constituem o ser humano, procurando considerá-lo como um todo. Fundamentalmente, este modelo que alia espiritualidade e procedimentos terapêuticos fornece um "idioma" que permite a expressão de experiências de sofrimento e aflição que em outros contextos não são consideradas legítimas.

O estudo do "sistema de cuidados da saúde" do Céu da Mantiqueira nos leva a repensar as fronteiras que comumente costumam ser estabelecidas entre "espiritualidade" e "terapia" e, portanto, entre uso "ritual" e "religioso" da ayahuasca e sua utilização "terapêutica". Vemos que estas divisões e fronteiras estão baseadas em pressupostos biomédicos e cartesianos. Assim, elas não dão conta do ponto de vista dos usuários desta bebida e ignoram aspectos relevantes que a noção de cura pode ter. Além disso, o uso dessas categorias dualistas fornece argumentos para a lógica proibicionista, definindo alguns tipos de usos da ayahuasca (no caso do Santo Daime, aqueles definidos como "rituais" e "religiosos") como legítimos, enquanto a outros tipos de utilização desta bebida, como o uso considerado "terapêutico", é conferido um status ao mesmo tempo ilegítimo e ilegal. É preciso, portanto, repensar e problematizar estas categorias e as fronteiras que costumam ser estabelecidas entre elas. 
1 O Alto Santo permaneceu praticamente restrito ao estado do Acre. Esta denominação refere-se a um conjunto de centros que se distinguem e funcionam de maneira autônoma, embora reivindiquem uma origem comum e tenham relações de proximidade (Goulart 2004). Já o CEFLURIS é a principal organização responsável pela expansão nacional e internacional da doutrina daimista.

2 Para fins deste trabalho, vou me referir à religião como Santo Daime e à bebida como daime.

3 Palavra que vem da língua quéchua e significa liana ou cipó dos mortos, da alma, dos espíritos (Luna 1986). Este termo pode referirse a uma bebida e é também o nome popular do principal componente desta bebida, o cipó Banisteriopsis sp. Embora as bebidas produzidas com este cipó sejam conhecidas pelo nome genérico ayahuasca, elas recebem mais de 40 denominações distintas e são utilizadas em diferentes contextos (Fericgla 1997).

4 De acordo com MacRae (1992), em 1985 a Divisão de Medicamentos do Ministério da Saúde (DIMED) incluiu o Banisteriopsis caapi na lista de produtos de uso proscrito em território nacional, sem a devida autorização do Conselho Federal de Entorpecentes (CONFEN). Pouco tempo depois, o CONFEN formou um grupo de trabalho para pesquisar o uso ritual da ayahuasca no Santo Daime e na União do Vegetal. Após a conclusão desta pesquisa, em 1987, a ayahuasca foi excluída da lista de produtos proscritos pela DIMED e liberada para uso ritual (MacRae 1992). A legalidade do uso ritual da ayahuasca foi novamente questionada em 1988 e 1994 , porém - CONFEN manteve sua decisão anterior de permitir a utilização da bebida em contextos rituais, incluindo as recomendações de que ela não fosse consumida por pessoas com problemas psiquiátricos, grávidas ou menores de idade. Em 2004, o Conselho Nacional Antidrogas (CONAD) suspendeu estas duas últimas restrições e instituiu um grupo multidisciplinar de trabalho para levantamento e acompanhamento do uso religioso da ayahuasca, bem como para a pesquisa de sua utilização terapêutica.

5 Velho elaborou o conceito de "mundo das drogas" a partir das obras de Georg Simmel (1971) e Alfred Schutz (1979), que sugerem "a possibilidade de classificar e identificar domínios da realidade que se distinguiriam através de fronteiras sociológicas e descontinuidades culturais" (Velho 1999:84). Estes espaços e domínios simbólicos são chamados genericamente de "mundos" (idem). Usando este conceito, Velho procura destacar "a necessidade de relativizar e contextualizar o estudo do que se classifica de droga" (1999:85).

6 Neste artigo não pretendo aprofundar estas discussões, apenas quero chamar a atenção para a complexidade do tema. Para maiores reflexões sobre o assunto, ver Labate (2005).

7 Entre os três grupos religiosos citados, é o grupo que conta com o maior número de participantes (cerca de 4500 de acordo com Brito 2002). Situa sua origem no baiano José Gabriel da Costa, conhecido como Mestre Gabriel. Foi criada em Porto Velho, Rondônia, no ano de 1961 (Labate 2004).

8 Foi criada na zona rural de Rio Branco (AC). Daniel Pereira de Matos é considerado seu fundador. Subdividiu-se posteriormente em várias igrejas, porém permanece praticamente restrita à cidade de Rio Branco (Araújo 1999).

9 Ver nota 4

10 Aqui as categorias "espiritualidade" e "terapia" são pensadas como tipos ideais (Weber 2002), ou seja, não existem em forma pura ou completamente independente.

11 Os participantes do Santo Daime referem-se aos lugares onde são realizados os seus rituais como "ponto" ou "igreja". Um "ponto" é uma unidade geralmente menor, mais recente e mais informal. Já a "igreja" é uma unidade mais consolidada dentro da estrutura institucional do CEFLURIS.

12 Os participantes do Santo Daime acreditam que, durante os rituais, a união das pessoas forma uma "corrente" de energia. Esta "corrente espiritual" constitui uma espécie de entidade coletiva a quem podem ser atribuídas características como harmonia/ desarmonia, força/ fraqueza etc. Nesse sentido, pode-se pensar na "corrente espiritual" como uma metáfora do próprio grupo.

13 Segundo Groisman (1991), para os participantes do Santo Daime, o ser humano seria constituído por três dimensões: o "aparelho", a "matéria" e o "espírito". As categorias "espírito" e "matéria" estariam relacionadas a duas outras categorias: o "Eu Inferior" e o "Eu Superior". O primeiro estaria ligado às motivações materiais e o segundo às motivações espirituais e ambos fariam parte da 
natureza do ser humano. Um dos objetivos dos rituais daimistas seria permitir "despertar" ou "revelar" o "eu superior", a natureza espiritual do ser humano (Groisman 1991).

14 Utilizo o termo "procedimentos" no lugar de "práticas" terapêuticas para chamar a atenção para a sua riqueza simbólica. Mais do que práticas, aqui estes procedimentos são pensados como conversões práticas de motivações simbólicas.

15 Uso expressões como "pessoas que trabalham profissionalmente na área da saúde" ou "profissionais da área da saúde" para me referir aos participantes do Céu da Mantiqueira que definiram sua profissão como sendo ligada à área da saúde, incluindo tanto a biomedicina quanto o campo das "terapias alternativas".

16 Jean Langdon (comunicação oral) propõe que os nomes destes setores sejam traduzidos respectivamente como "familiar", "popular" e "profissional". Segundo Kleinman (1973), o primeiro destes setores envolve principalmente a família, mas inclui também a rede social e a comunidade. Ele destaca o papel central deste setor. Já o setor "popular" é formado pelos especialistas na área da saúde que não são profissionais, enquanto o setor "profissional" é constituído pela biomedicina e pelas tradições de cura e medicinas "nativas" que são profissionalizadas (1973:87).

17 O conceito de "limpeza" tem um papel importante no paradigma terapêutico daimista. Trata-se de um conceito bastante denso e sintético. A "limpeza" pode acontecer em nível individual ou grupal e pode referir-se à dimensão espiritual, à dimensão material ou a ambas. Este conceito costuma ser relacionado às "catarses fisiológicas" (Peláez 1996: 84) experienciadas durante os rituais (vômitos, diarréias, choros etc.). A "limpeza" tem uma conotação positiva, pois acredita-se que é através dela que se pode ter acesso ao conhecimento e às curas proporcionadas pela ingestão do daime.

18 "Aparelho" é um conceito muito usado pelos participantes do Céu da Mantiqueira. De acordo com uma definição êmica, refere-se a um médium que cede seu corpo para que, através dele, as entidades possam "trabalhar". Desta maneira, ele se torna um "aparelho mediúnico" ou "canal".

19 Sede do CEFLURIS, localizada no município de Pauiní (AM).

20 Os participantes do Céu da Mantiqueira concebem o ser humano como sendo formado por vários "corpos". Entre estes, destacamse o "corpo físico", que corresponde ao corpo reconhecido pela biomedicina; o "corpo emocional", que está ligado ao domínio das emoções e dos sentimentos; o "corpo mental", que está ligado com o raciocínio, a lógica e os pensamentos; e o "corpo espiritual", que está relacionado à alma e representa a conexão com a "dimensão espiritual". Entre esses corpos, o "corpo físico" seria o mais denso, e esta densidade iria diminuindo até chegar ao "corpo espiritual", que seria o mais sutil.

21 Segundo Edilene Coffaci de Lima e Beatriz Caiuby Labate (2005), o termo usado para designar o Phyllomedusa sp tem sido grafado de diferentes maneiras, entre elas kampu, kampo, kampô e, mais recentemente, kambô. A grafia kampu é usada pelos Kaxinawá, enquanto os Katukina utilizam kampo e kampô (Lima \& Labate 2005). Utilizo aqui kambô, pois esta é a forma usada pelos participantes do Céu da Mantiqueira.

22 Segundo Eduardo Galvão e Roberto da Matta (1955 e 1973, respectivamente, citados em Lima \& Labate 2005), no panorama amazônico a "panema" é entendida como incapacidade, principalmente para caçar. Equivale a uma falta de disposição generalizada.

23 A noção daimista de comunidade não é necessariamente definida pelo fato de seus membros co-habitarem o mesmo espaço geográfico. Pode também ser uma "comunidade simbólica" (Turner 1969), caracterizada pelo compartilhamento de experiências, práticas, valores e crenças comuns (Groisman \& Sell 1996).

24 Segundo as narrativas das pessoas que trabalham profissionalmente na área da saúde ligadas ao Céu da Mantiqueira, existem alguns casos nos quais não é indicado tomar daime: trata-se de pessoas diagnosticadas como psicóticas, esquizofrênicas ou que estejam tomando medicação com base na fluoxetina. No Céu da Mantiqueira, para evitar que as pessoas tomem daime sem ter a devida orientação, é realizada uma entrevista e uma anamnese com os "iniciantes", ou seja, as pessoas que participam do ritual pela primeira vez.

25 Segundo os psiquiatras que eu entrevistei, a princípio os únicos medicamentos incompatíveis com o daime são os inibidores de recaptação de serotonina com base na fluoxetina. De acordo com eles, outros tipos de medicamentos podem ser usados sem problemas. 
26 Utilizo o termo "terapeutização" para indicar um processo que considero diferenciado e mais amplo que a "medicalização", pois, apesar de incluir também a medicalização, não se restringe a ela.

27 Ver nota 20.

28 Os participantes do Santo Daime concebem a realidade como sendo formada pela interação entre duas dimensões: o "mundo material" e o "mundo espiritual". A primeira diz respeito aos fenômenos empíricos da vida cotidiana, o mundo visível, enquanto a segunda está relacionada principalmente ao mundo implícito ou invisível. De acordo com Groisman (1991), mais do que dois mundos distintos e separados, a existência destas duas dimensões corresponde a duas formas de perceber o todo.

29 Laplantine vê o pensamento religioso como uma "forma de expressão totalizante do social" (1991: 217). 


\section{REFERÊNCIAS BIBLIOGRÁFICAS}

ARAÚJO, Wladimir Sena. 1999. Navegando sobre as Ondas do Daime. História, cosmologia e ritual da Barquinha. Campinas: Editora da Unicamp.

BRITO, Glacus de Souza. 2002. "Farmacologia Humana da Hoasca (chá preparado de plantas alucinógenas usado em contexto ritual no Brasil)". In B. Labate \& W. S. Araújo (orgs.) O Uso Ritual da Ayahuasca. Campinas: Editora Mercado de Letras.

CAPRARA, Andréa. 1998. “Médico Ferido: Omulu nos labirintos da doença”. In P. C. Alves \& M. C. Rabelo (orgs.) Antropologia da Saúde: traçando identidades e explorando fronteiras. Rio de Janeiro: Relume-Dumará.

DaMATTA, Roberto. 1973. “Panema: uma tentativa de análise estrutural”. In Ensaios de Antropologia Estrutural. Petrópolis: Vozes.

FERICGLA, Joseph Ma. 1997. Al Tras/uz de la Ayahuasca. Antropología cognitiva, oniromancia y conciencias alternativas. Barcelona: Los libros de la liebre de marzo.

FREIRE, Maria Alice Campos \& Isabel Facchine Barsé. 2000. Florais da Amazônia. Porto Alegre: Hércules.

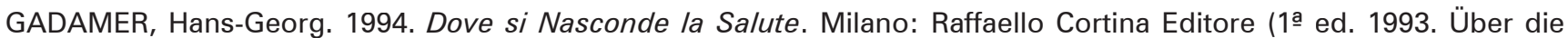
Verborgenheit der Gesundheit).

GALVÃO, Eduardo. 1976. Santos e Visagens. São Paulo: Editora Nacional, Brasília: Instituto Nacional do Livro.

GROISMAN, Alberto. 1991. “Eu Venho da Floresta”: ecletismo e praxis xamânica daimista no Céu do Mapiá. Dissertação de Mestrado em Antropologia Social. Florianópolis: Universidade Federal de Santa Catarina.

GROISMAN, Alberto \& Ari Sell. 1996. “Healing Power: cultural-neurophenomenological therapy of Santo Daime”. In M. Winkelman \& W. Andritzky (eds.) Yearbook of Cross-Cultural Medicine and Psychotherapy. Berlin: Verlag.

GOULART, Sandra. 2004. Contrastes e Continuidades em uma Tradição Amazônica: as religiões da ayahuasca. Tese de Doutorado em Ciências Sociais. Campinas: Unicamp.

KLEINMAN, Arthur. 1973. "Concepts and a Model for the Comparison of Medical Systems as Cultural Systems". Social Science and Medicine 12.

1980. Patients and Healers in the Context of Culture. Berkeley: University of California Press.

LABATE, Beatriz. 2002. “A Literatura Brasileira sobre as Religiões Ayahuasqueiras”. In B. Labate \& W. S. Araújo (orgs.) O Uso Ritual da Ayahuasca. Campinas: Editora Mercado de Letras.

. 2004. A Reinvenção do Uso da Ayahuasca nos Centros Urbanos. Campinas: Mercado de Letras.

2005. “Dimensões Legais, Éticas e Políticas da Expansão do Consumo da Ayahuasca”. In B. Labate \& S. Goulart (orgs.) O Uso Ritual das Plantas de Poder. Campinas: Editora Mercado de Letras.

LAPLANTINE, François. 1991. Antropologia da Doença. São Paulo: Martins Fontes.

LIMA, Edilene Coffaci de \& Beatriz Caiuby Labate. 2005. “De Kampô a Phyllomedusa bicolor: velhos e novos usos da secreção do sapo-verde dos Katukina". Comunicação apresentada no XXIX Encontro Anual da ANPOCS. 
LUNA, Luis Eduardo. 1986. Vegetalismo: shamanism among the mestixo population of the Peruvian Amazon. Stockholm: Almquist and Wiskell International.

MacRAE, Edward. 1992. Guiado pela Lua: xamanismo e uso ritual da ayahuasca no culto do Santo Daime. São Paulo: Editora Brasiliense.

MALUF, Sônia Weidner. 2003. "Mitos Coletivos e Narrativas Pessoais. Cura, ritual e trabalho terapêutico nas culturas da Nova Era" (manuscrito).

MONTERO, Paula. 1985. Da Doença à Desordem: a magia na Umbanda. São Paulo: Graal.

PELÁEZ, Maria Cristina. 1996. No mundo se cura tudo, Interpretações sobre a cura espiritual no Santo Daime. Dissertação de Mestrado em Antropologia Social. Florianópolis: UFSC.

ROSE, Isabel Santana de. 2002. A Cura na Doutrina do Santo Daime - Um estudo sobre o Céu da Mantiqueira. Monografia de conclusão do curso de graduação em Ciências Sociais. Campinas: UNICAMP.

. 2005. Espiritualidade, Terapia e Cura. Um estudo sobre a expressão da experiência no Santo Daime. Dissertação de Mestrado em Antropologia Social. Florianópolis: UFSC.

SCHUTZ, Alfred. 1979. Fenomenologia e Relações Sociais. Rio de Janeiro: Zahar.

SIMMEL, Georg. 1971. On Individuality and Social Forms. Donald Levine (org.). Chicago: University of Chicago Press.

SOUZA, Moises Barbosa de, Carlito Cataiano, Terri Valle de Aquino, Edilene Coffaci de Lima \& Margarete K. Mendes. 2002. “Dicionários - Bichos e Plantas. Anfíbios". In M. C. da Cunha \& M. B. de Almeida (orgs.) Enciclopédia da Floresta. O Alto Juruá: práticas e conhecimentos das populações. São Paulo: Companhia das Letras.

TURNER, Victor. 1969. The Ritual Process. London: Routledge \& Kegan Paul.

VELHO, Gilberto. 1997. “Drogas, Níveis de Realidade e Diversidade Cultural”. In M. de M. Ribeiro \& S. D. Seibel (orgs.) Drogas: hegemonia do cinismo. São Paulo: Fundação Memorial da América Latina.

. 1999. “Dimensão Cultural e Política do Mundo das Drogas". In Projeto e Metamorfose. Antropologia das sociedades complexas. Rio de Janeiro: Jorge Zahar Editor.

WEBER, Max. 2002. Conceitos Básicos de Sociologia. São Paulo: Centauro Editora. 


\section{Repensando as Fronteiras entre Espiritualidade e Terapia: Reflexões sobre a "cura" no Santo Daime}

\section{RESUMO}

O Céu da Mantiqueira é uma comunidade do Santo Daime localizada no sul do estado de Minas Gerais e considerada pelos seus participantes como sendo um "centro de cura". Neste artigo, faço uma análise do "sistema de cuidados da saúde" desta comunidade, realizando um levantamento dos principais procedimentos terapêuticos utilizados. Estes procedimentos terapêuticos são provenientes de diversas fontes, tais como a própria doutrina daimista, outras tradições religiosas, grupos indígenas, as chamadas "terapias alternativas" e a biomedicina. A partir deste levantamento proponho uma reflexão a respeito das fronteiras que costumam ser estabelecidas entre as categorias "espiritualidade" e "terapia". O que eu sugiro é que, neste contexto, estas dimensões não podem ser consideradas separadamente, ao contrário, interpenetram-se e formam um continuum espiritual-terapêutico.

PALAVRAS-CHAVE: Santo Daime; cura; continuum espiritual-terapêutico.

\section{Rethinking the Boundaries between Spirituality and Therapy: Reflections about "healing" in Santo Daime}

\section{ABSTRACT}

The Santo Daime community Céu da Mantiqueira, located in the south of the state of Minas Gerais (Brazil), is considered a "healing center" by its participants. In this essay, I develop an analysis of the community's "health care system" and a survey of the essential therapeutic procedures. These therapeutic procedures come from several sources, including: the Santo Daime's doctrine itself, other religious traditions, Brazilian indigenous groups, the so-called "alternative therapies" and biomedicine. Based on this survey, I suggest a reconsideration of the boundaries that are commonly established between the categories of "spirituality" and "therapy". My contention is that, in this context, these dimensions cannot be separately considered; on the contrary, they are interpenetrated and form a spiritual-therapeutic continuum. KEY WORDS: Santo Daime; healing; spiritual-therapeutic continuum.

Recebido em 16/01/2006

Aprovado em 16/04/2006 